\title{
The effect of the Duration of Orthognathic Surgery on Plasma Concentration of Interleukin 6
}

\author{
Mandana Sattari ${ }^{1 *}$, Ali Peymani Mojaver ${ }^{2}$, Hossein Behnia ${ }^{3}$, Golnaz Kavand ${ }^{4}$, Hassan Darbandi-Tamijani ${ }^{1}$ \\ ${ }^{1}$ Department of Immunology, Medical School, Shahid Beheshti University of Medical Sciences, Tehran. Iran. \\ ${ }^{2}$ Department of Maxillo-facial Surgery, Dental School, Rafsanjan University of Medical Sciences, Rafsanjan, Iran. \\ ${ }^{3}$ Department of Maxillo-facial Surgery, Dental School, Shahid Beheshti University of Medical Sciences, Tehran, Iran. \\ ${ }^{4}$ Departments of Preventive and Community Dentistry, University of Iowa, College of Dentistry, Iowa, USA.
}

Received: 11 Nov 2013

Revised : 12 Dec 2013

Accepted: 29 Dec 2013

Corresponding Authors: Mandana Sattari

Department of Immunology, Medical School, Shahid Beheshti University of Medical Sciences.

Phone: $+98-2122439970$

Fax: (021) 23872545

E-mail: mandana.sattari@gmail.com

\begin{abstract}
Background: The cytokines have a major role in the inflammatory response to surgery and trauma. They have local effects of mediating and maintaining the inflammatory response to tissue injury, and also initiate some of the systemic changes which occur. IL-6 is one of the above mentioned cytokines, but it is not clear whether the duration of trauma or surgery has some effect on IL-6 level, so the aim of this study was to investigate the relationship between plasma levels IL6 and duration of orthognathic surgery.

Materials and Methods: Twenty eight patients underwent orthognathic surgery were enrolled in this study. Blood samples were collected one day before and 4 hours after surgery for assessment the levels of plasma IL-6 which was measured by enzyme-linked immunosorbent essay.

Results: We found a significant elevation of plasma IL-6 level at 4 hours after surgery $(\mathrm{P}<0.05)$. Moreover, the elevation of plasma IL-6 level was correlated with the duration of surgery.

Conclusion: IL-6 is an important inflammatory mediator that its concentration is increased with the duration of surgery.
\end{abstract}

Keywords: Orthognathic surgery; Interleukin-6; Duration of surgery; Acute phase response

Please cite this article as: Sattari M, Peymani Mojaver A, Behnia H, Kavand G, Darbandi-Tamijani H. The effect of the Duration of Orthognathic Surgery on Plasma Concentration of Interleukin 6. Res Mol Med. 2013; 1 (3): 34-37

\begin{abstract}
Introduction
Orthognathic surgery is a surgery to correct conditions of the jaw and face related to structure, growth, sleep apnea, TMJ disorders, malocclusion problems owing to skeletal disharmonies, or other orthodontic problems that cannot be easily treated with braces. It is also used in treatment of congenital conditions like cleft palate (1). Bones can be cut and re-aligned, then held in place with either screws or plates. Orthognathic surgery can also be referred to as corrective jaw surgery (3). It was known that surgery at any location in the body leads to surgical stress response and alterations in normal body (2). Several studies demonstrated that pro-inflammatory cytokines such as IL-1 $\beta$ (Interleukin-1beta), IL-6, IL-8, and TNF- $\alpha$ (Tumor necrosis factor-alpha) transiently increase in the serum or plasma of injured patients $(3,4)$. IL-6 is
\end{abstract}

a multifunctional cytokine that was originally identified as a B-cell growth factor-2 (BCGF-2). Since then, IL-6 has been found to have a wide array of additional activities, including effects on vascular endothelial cells, and neurons. In addition, IL-6 is closely related to other cytokines with diverse and, in some cases, redundant, activities, such as IL-1 and TNF (5). IL-6 is expressed at high levels in several inflammatory diseases, including systemic juvenile arthritis, systemic Lupus erythematosus, Crohn's disease, and rheumatoid arthritis (6).

One of the most important systemic actions of IL-6 is induction of the acute phase response and induction the synthesis of acute phase proteins (APPs) by liver (7-9). One of the other aspects of the acute phase response, which regulated at least in part by IL-6, 
includes the induction of fever $(8,10)$. Inflammatory cytokines acts on the hypothalamus to induce fever within several hours of the onset of acute phase inflammatory response. The proinflammatory IL-1, IL- 6 and TNF- $\alpha$ have been most investigated for their pyrogenic action, with most focus on IL-1 and TNFa (11). However, the concept was challenged when specific blockade of either IL-1 or TNF $\alpha$ activity did not diminish the febrile response to bacterial byproducts such as LPS and it was suggested that during infection, fever could occur independently of IL-1 or TNF activity (12).

In other hand, it has been proved in the maxillofacial area that the level of IL-6 in plasma increases after different operations (13). Moreover, IL-6 has been thought to be associated with incidence of postoperative complications and the duration of surgery (14-17).

Granulocyte Macrophage Colony stimulating Factor (GM-CSF), interferon (INF), interleukin (IL)-1 $\beta$, IL2 , IL-6, IL-8, IL-10 and tumor necrosis factor (TNF)$\alpha$ were detected in the synovial fluid from the temporomandibular joint (TMJ) spaces of temporomandibular disorder (TMD) patients (18). Since one of the aims of orthognathic surgery is to correct the temporomandibular disorders, it is not clear whether it can lower the IL-6 concentration or not. In addition, there is no study about the effect of duration of maxillofacial surgery on the level of inflammatory cytokines, so, the main objective of this study is to investigate the relationship between plasma level of IL-6 and duration of surgery, in patients undergoing orthognathic surgery.

\section{Materials and Methods \\ Patients}

28 patients (14 male and 14 female mean age, $23.7 \pm$ 7.94 years old) were enrolled in this study. Patients over 70 years old or less than 18 years old were excluded. No patients had apparent inflammatory conditions before surgery. None of them had any disorder of immune system or metabolism or endocrine or liver cirrhosis. Preoperative informed consent was obtained from enrolled patients. This study has been approved by the ethical committee of the research center of Dental school of Shahid Beheshti University of Medical Sciences. Fourteen of them underwent one jaw and the other fourteen patients underwent two jaw osteotomy. Operations were performed with ordinary general anesthesia and Bilateral Sagittal Split Ramus Osteotomy (BSSRO) and Lefort1 Osteotomy with down fracture for maxillae. The operation time was measured from intubation to extubation. All patients were routinely administered 8mg Dexamethasone and $1 \mathrm{~g}$ Cephazolin intravenously $0.5 \mathrm{~h}$ before and $3 \mathrm{~h}$ after surgery.

\section{Blood samples}

Blood samples were collected one day before and 4 hours after surgery. Blood was drawn into sterile tubes containing heparin. The plasma samples were separated by centrifugation at $1500 \mathrm{~g}$ in $15 \mathrm{~min}$; the supernatant was stored at $-80{ }^{\circ} \mathrm{C}$ until analysis.

\section{IL-6 analysis}

The plasma level of IL- 6 was measured by enzyme linked immunosorbent assay (ELISA) with a Human Interleukin-6 ELISA Kit (Biosource Inc. Belgium). The sensitivity for IL-6 was $2 \mathrm{pg} / \mathrm{ml}$.

\section{Measurement of body temperature}

Axillary's body temperature was measured 24hours before surgery. Classic mercury-in-glass thermometer was used for axillary recording.

\section{Statistical Analysis}

Descriptive statistics were followed by Pearson correlation coefficient and Multiple linear regression were used for comparison plasma level of IL-6 and body temperature; and plasma level of IL-6 and duration and type of surgery, and paired t test for assessing the difference in the level of IL- 6 between before and after surgery.

\section{Results}

Table 1 shows the range, mean and standard deviation (SD) of age, and duration of surgery. 6 patients $(20 \%)$ had post-operative fever.

Table 1. Descriptive statistics of age and duration of surgery. $(\mathrm{n}=28)$

\begin{tabular}{cccc}
\hline Variable & Range & Mean & SD \\
\hline Age & $18-59$ & 23.7 & 7.94 \\
Duration of surgery & $3-7$ & 4.8 & 1.21 \\
\hline
\end{tabular}

Descriptive statistics of IL-6 levels are shown in table 2. Plasma level of IL-6 increased $4 \mathrm{~h}$ after surgery, and it was statistically significant $(\mathrm{P}<0.05)$.

Table 2. Descriptive Statistics of plasma IL-6 before and 4 hours after the surgery. $(\mathrm{n}=28)$

\begin{tabular}{ccccccc}
\hline \multirow{2}{*}{ Variables } & Range & Mean & SD & \multicolumn{2}{c}{$\mathbf{9 5 \%}$ C I for mean } \\
\cline { 5 - 6 } & & & & Lower & Upper \\
\hline IL-6* & Before & $7-104$ & 20.6 & 21.56 & 12.55 & 28.65 \\
& After & $52-345$ & 134.54 & 85.02 & 102.78 & 166.28 \\
\hline
\end{tabular}

*pg per ml

There was a significant elevation in IL-6 concentration after orthognatic surgery $(\mathrm{P}<0.05)$. Multiple regression $\left(\mathrm{R}^{2}=0.238, \mathrm{P}<0.05\right)$ showed that 
duration of surgery having relationship with plasma IL-6, in other word, with increasing the duration of surgery, the level of IL- 6 will be increased, but we could not find any relationship between IL-6 concentration and fever. We also found a positive correlation between postoperative level of IL-6 and fever.

\section{Discussion}

Acute-phase response (APR) is initiated in response to injury. The aim of this reaction is to prevent ongoing tissue damage, enhance body defense against pathogens and activate the repair process (19). APR is characterized by leukocytosis, fever, as well as induction of synthesis of various acute-phase proteins (APPs) which leads to changes in the plasma concentrations of them (20). The main stimulator of APP production is IL-6, produced during inflammatory processes and acts on hepatocytes in order to produce APPs (21). IL-6 is produced by various types of cells including $\mathrm{T}$ cells, B cells, monocytes etc, and plays a major role in host defense mechanisms, regulation of immune response and acute phase reactions (22). High level of this cytokine was found in sinovial fluids of patients with temporomandibular joint damage (18). Cytokine production reflects the degree of tissue trauma, so cytokine release is lowest with the least invasive and traumatic procedures $(23,24)$. We evaluated the plasma level of IL-6 and post operative fever only 4 hours after orthognathic surgery, rather than a longer term, because to exclude interfering factors such as post-operative infection of the surgical wound which may happen in the longer term. Furthermore, it was shown that the plasma level of IL- 6 can be detected at 2 to 6 hours after incision (13). We found a significant elevation of plasma IL-6 level at 4 hours after surgery $(\mathrm{P}<0.05)$. Moreover, the elevation of plasma IL-6 level was correlated with the duration of surgery $(\mathrm{P}<0.05)$, which was similar to those observed in the previous studies $(25,26)$. The correlation of the IL- 6 level with the duration of surgery is generally associated with this fact that IL-6 level is a marker reflecting the magnitude of surgical trauma (27-29).

Chachkhiani et al. reported a transient elevation in IL-6 concentration in plasma $12 \mathrm{hrs}$ after resection of colorectal cancer but after 24 and $48 \mathrm{hrs}$ there was not any difference with the levels before surgery (30). We also found a significant increase in IL-6 level, but due to ethical considerations we cannot take any further samples after 4 hours.

We could not find any significant correlation between fever and IL-6 concentration in plasma, whereas Baigri et al. (15) and Miyawaki et al. (25) reported significant correlation between fever and IL-6 concentration. The difference between the results may be due to the injection of corticosteroids before and immediately after the surgery in our study which in turn can decrease the production PGE2 and other arachidonic acid metabolites which act as pyrogen mediators. It is concluded that IL-6 is an important inflammatory mediator that its concentration is increased with the duration of surgery, in other word, there is a direct correlation between its concentration and the amount of the trauma during the surgery.

\section{Acknowledgements}

The authors would like to thank the Oral and Maxillofacial Surgery department of Shahid Beheshti University of Medical Sciences.

\section{References}

1. Bill J, Proff P, Bayerlein T, Blens T, Gedrange T, Reuther J. Orthognathic surgery in cleft patients. J Craniomaxillofac Surg. 2006; 34 Suppl 2: 77-81. PMID: 17071397

2. Thomas S, Balasubramanian KA. Role of intestine postsurgical complications Involvement of free radicals. Free Radic Biol Med. 2004; 36: 745. PMID: 14990353

3. Feniger-Barish R, Ran M, Zaslaver A, Ben-Baruch A. Differential modes of regulation of CXC chemokine-induced internalization and recycling of human CXCR1 and CXCR2. Cytokine. 1999; 11 (12): 996-1009. PMID: 10623425

4. Igonin AA, Armstrong VW, Shipkova M, Lazareva NB, Kukes VG, Oellerich M. Circulating cytokines as markers of systemic inflammatory response in severe community-acquired pneumonia. Clin Biochem. 2004; 37: 204. PMID: 14972642

5. Kishimoto T, Akira S, Narazaki M, Taga T. Interleukin-6 family of cytokines and gp130. Blood. 1995; 86: 1243-54. PMID: 7632928

6. Gabay C. Interleukin-6 and chronic inflammation. Arthritis Res Ther. 2006; 8 (Suppl 2): S3. PMID: 16899107

7. Miyawaki T, Maeda S, Shimada M. Elevation of plasma interleukin-6 level in patients undergoing oral and maxillofacial surgery. Oral Surg Oral Med Oral Pathol Oral Radiol Endod. 1996; 81: 15-20. PMID: 8850476

8. Van Snick J. Interleukin 6: An overview. Annu Rev Immunol. 1990; 8: 253-78. PMID: 2188664

9. Wong PK, Campbell IK, Egan PJ, et al. The role of the interleukin-6 family of cytokines in inflammatory arthritis and bone turnover. Arthritis Rheum. 2003; 48: 1177-89. PMID: 12746890

10. Nishimoto N, Kishimoto T. Interleukin 6: From bench to bedside. Nat Clin Pract Rheumatol. 2006; 2: 619-26. PMID: 17075601

11. Conti B, Tabarean I, Andrei C, Bartfai T. Cytokines and fever. Front Biosci. 2004; 9: 1433-49. PMID: 14977558

12. Dinarello CA. Infection, fever, and exogenous and endogenous pyrogens: some concepts have changed. J Endotoxin Res. 2004; 10 (4): 201-22. PMID: 15373964

13. Miyawaki T, Maeda S, Shimada M. Elevation of plasma interleukin-6 level in patients undergoing oral and maxillofacial 
surgery. Oral Surg Oral Med Oral Pathol Oral Radiol Endod. 1996; 81: 15-20. PMID: 8850476

14. Oka Y, Murata A, Nishijima J, Yasuda T, Hiraoka N, Ohmachi $\mathrm{Y}$, et al. Circulating interleukin 6 as a useful marker for predicting post-operative complications. Cytokine. 1992; 4 (4): 298-304. PMID: 1515554

15. Shenkin A, Fraser WD, Series JJ, et al. The serum interleulin-6 response to elective surgery. Lymphokine Res. 1989; 8 (2): 123-7. PMID: 2786596

16. Baigrie RJ, Lamont PM, Dallman M, Morris PJ. The release of interleukin-1 $\beta$ (IL-1) precedes that of interleukin 6(IL-6) in patients undergoing major surgery. Lymphokine Cytokine Res. 1991; 10: 253-6. PMID: 1932368

17. Baigrie RJ, Lamont PM, Kwiatkowski D, Dallman MJ, Moris PJ. Systemic cytokine response after major surgery. Br J Surg. 1992; 79: 757-60. PMID: 1393463

18. Kim YK, Kim SG, Kim BS, Lee JY, Yun PY, Bae JH Analysis of the cytokine profiles of the synovial fluid in a normal temporomandibular joint: preliminary study. J Craniomaxillofac Surg. 2012; 40 (8): e337-41.16. PMID: 22425498

19. Baumann H, Gauldie J. The acute phase response. Immunol Today. 1994; 15 (2): 74-80. PMID: 7512342

20. Gabay C, Kushner I. Acute-phase proteins and other systemic responses to inflammation. N Engl J Med. 1999; 340 (6): 448-54. PMID: 9971870

21. Castell JV, Gomez-Lechon MJ, Davis M, Hirano T, Kishimoto T, Heinrich PC. Recombinant human interleukin-6 (IL-6/BSF$2 / \mathrm{HSF}$ ) regulates the synthesis of acute phase proteins in human hepatocytes. FEBS Lett. 1988; 232: 347-50. PMID: 2454206

22. Aarden LA, De Groot ER, Schaap OL, Lansdrop PM Production of hybridoma growth factor by human monocytes. Eur J Immunol. 1987; 17: 1411-16. PMID: 3500054
24. Desborough JP. The stress response to trauma and surgery. Br J Anaesth. 2000; 85 (1): 109-17. PMID: 10927999

23. Finnerty CC, Mabvuure NT, Ali A, Kozar RA, Herndon DN. The surgically induced stress response. JPEN J Parenter Enteral Nutr. 2013; 37(5 Suppl): 21S-9S. PMID: 24009246

25. Miyawaki T, Maeda S, Koyama Y, Fukuoka R, Shimada M. Elevation of plasma interleukin-6 level is involved in postoperative fever following major oral and maxillofacial surgery. Oral Surg Oral Med Oral Pathol Oral radiol Endod. 1998; 85: 14652. PMID: 9503447

26. Miyaoka K, Iwase M, Suzuki R, Kondo G, Watanabe H, Ito D, et al. Clinical evaluation of circulating interleukin-6 and interleukin-10 levels after surgery-induced inflammation. J Surg Res 2005; 125 (2): 144-50. PMID: 15854666

27. Murata A, Ogawa M, Yasuda T, Nishijima J, Oka Y, Ohmachi $\mathrm{Y}$, et al. Serum interleukin 6, C-reactive protein and pancreatic secretory trypsin inhibitor (PSTI) as acute phase reactants after major thoracoabdominal surgery. Immunol Invest. 1990; 19: 2718. PMID: 2114355

28. Oka Y, Murata A, Nishigima J, Yasda T, Hiraoka N, Ohmachi $\mathrm{Y}$, et al. Circulating IL-6 as a useful marker for predicting postoperative complications. Cytokine. 1992; 4: 298-304. PMID: 1515554

29. Ohzato H, Yoshizaki K, Nishimoto N, Ogata A, Tagoh H, Monden M, et al. Interleukin- 6 as a new indicator of inflammatory status: detection of serum levels of Interleukin-6 and C-reactive protein after surgery. Surg. 1992; 111 (2): 201-9. PMID: 1736391

30. Chachkhiani I, Gürlich R, Maruna P, Fraško, Lindner J. The post-operative stress response and its reflection in cytokine network and Leptin plasma levels. Physiol Res. 2005; 54: 279-85. PMID: 15588161 